\title{
A surface biotinylation strategy for reproducible plasma membrane protein purification and tracking of genetic and drug- induced alterations
}

Katrin Hörmann ${ }^{1}$, Alexey Stukalov ${ }^{1,2}$, André C. Müller ${ }^{1}$, Leonhard X. Heinz ${ }^{1}$, Giulio Superti-Furga ${ }^{1,3^{*}}$, Jacques Colinge ${ }^{1,4^{*}}$, Keiryn L. Bennett ${ }^{1^{*}}$

${ }^{1}$ CeMM Research Center for Molecular Medicine of the Austrian Academy of Sciences, Vienna, Austria ${ }^{2}$ Current address: Max Planck Institute for Biochemistry, Munich, Germany

${ }^{3}$ Center for Physiology and Pharmacology, Medical University of Vienna, Vienna, Austria

${ }^{4}$ Current address: Institut de Recherche en Cancérologie de Montpellier, Montpellier, France

"Corresponding authors:

Giulio Superti-Furga

CeMM Research Center for Molecular Medicine of the Austrian Academy of Sciences

Lazarettgasse 14, AKH BT 25.3

1090 Vienna, Austria

$\mathrm{T}+43-1-40160-70001$

$F+43-1-40160-970000$

gsuperti@cemm.oeaw.ac.at

Jacques Colinge

Cancer Bioinformatics and Systems Biology

Institut de Recherche en Cancérologie de Montpellier Inserm U1194

Université de Montpellier, Institut regional du Cancer Montpellier, Campus Val d'Aurelle 
F-34298 Montpellier Cedex 5, France

$\mathrm{T}+33 .(0) 4.67 .61 .23 .92$

$\mathrm{F}+33 .(0) 4.67 .61 .37 .87$

Keiryn L. Bennett

CeMM Research Center for Molecular Medicine of the Austrian Academy of Sciences

Lazarettgasse 14, AKH BT 25.3

1090 Vienna, Austria

$\mathrm{T}+43-1-40160-70010$

$F+43-1-40160-970000$

kbennett@cemm.oeaw.ac.at 


\section{Supporting Information}

Table of contents

\begin{tabular}{|c|c|}
\hline Figure S1 & $\begin{array}{l}\text { Qualitative and quantitative reproducibility of sulfo-NHS-SS- } \\
\text { biotinylation using competitive biotin elution on HAP1 cells }\end{array}$ \\
\hline Figure S2 & $\begin{array}{l}\text { Localization profile for co-purified interactors of annotated } \\
\text { plasma membrane proteins }\end{array}$ \\
\hline Supplementary Table 1 & $\begin{array}{l}\text { Subsets within the reproducible set of proteins obtained with } \\
\text { sulfo-NHS-SS-biotinylation coupled to biotin elution }\end{array}$ \\
\hline Supplementary Table 2 & Surface protein abundance changes upon PIGS KO \\
\hline Supplementary Table 3 & $\begin{array}{l}\text { Surface protein abundance changes upon tunicamycin } \\
\text { treatment }\end{array}$ \\
\hline Supplementary Table 4 & $\begin{array}{l}\text { Protein-protein interaction data for surface proteins affected } \\
\text { by tunicamycin treatment }\end{array}$ \\
\hline
\end{tabular}

Supplementary Tables 1-4 are provided as individual xls files 
Figure S1: Qualitative and quantitative reproducibility of sulfo-NHS-SS-biotinylation using competitive biotin elution on HAP1 cells
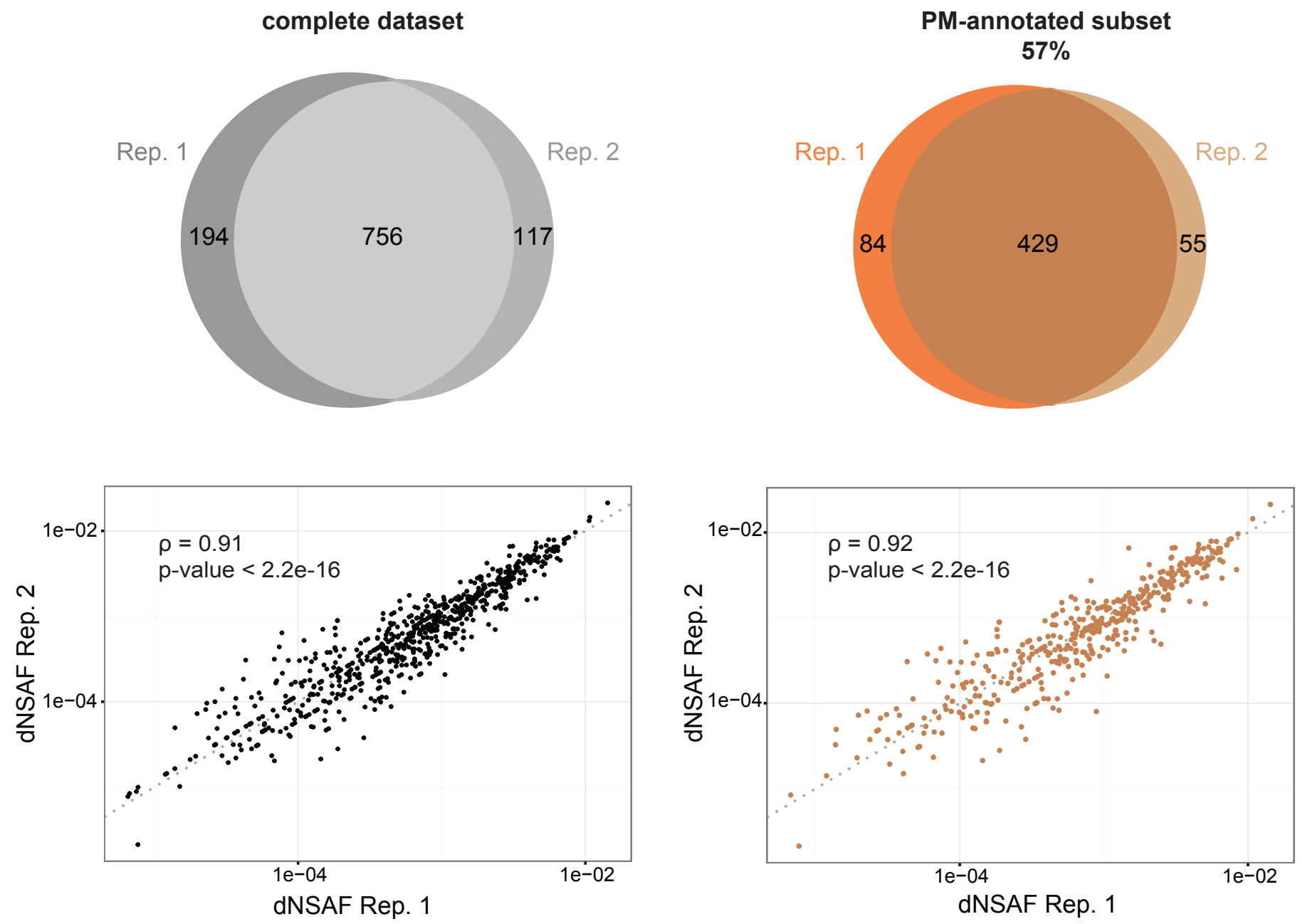
Figure S2: Localization profile for co-purified interactors of annotated plasma membrane proteins

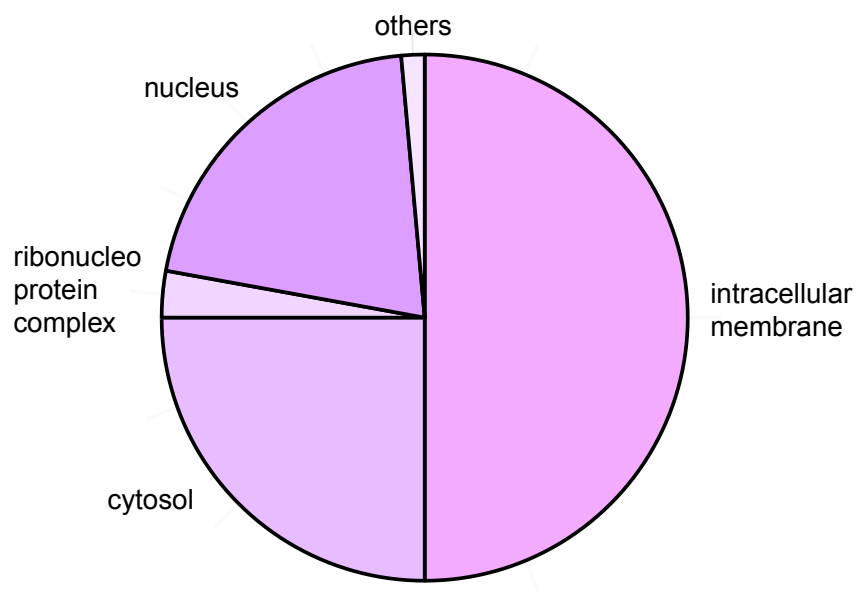

